\title{
Is cycle network expansion cost-effective? A health economic evaluation of cycling in Oslo
}

\author{
Admassu N. Lamu ${ }^{1 *}$ (D), Abdulrahman Jbaily², Stéphane Verguet ${ }^{2}$, Bjarne Robberstad ${ }^{1}$ and Ole Frithjof Norheim ${ }^{1,2}$
}

\begin{abstract}
Background: Expansion of designated cycling networks increases cycling for transport that, in turn, increases physical activity, contributing to improvement in public health. This paper aims to determine whether cycle-network construction in a large city is cost-effective when compared to the status-quo. We developed a cycle-network investment model (CIM) for Oslo and explored its impact on overall health and wellbeing resulting from the increased physical activity.

Methods: First, we applied a regression technique on cycling data from 123 major European cities to model the effect of additional cycle-networks on the share of cyclists. Second, we used a Markov model to capture health benefits from increased cycling for people starting to ride cycle at the age of 30 over the next 25 years. All health gains were measured in quality-adjusted life years (QALYS). Costs were estimated in US dollars. Other data to populate the model were derived from a comprehensive literature search of epidemiological and economic evaluation studies. Uncertainty was assessed using deterministic and probabilistic sensitivity analyses.

Results: Our regression analysis reveals that a $100 \mathrm{~km}$ new cycle network construction in Oslo city would increase cycling share by $3 \%$. Under the base-case assumptions, where the benefits of the cycle-network investment relating to increased physical activity are sustained over 25 years, the predicted average increases in costs and QALYs per person are $\$ 416$ and 0.019 , respectively. Thus, the incremental costs are $\$ 22,350$ per QALY gained. This is considered highly cost-effective in a Norwegian setting.

Conclusions: The results support the use of CIM as part of a public health program to improve physical activity and consequently avert morbidity and mortality. CIM is affordable and has a long-term effect on physical activity that in turn has a positive impact on health improvement.
\end{abstract}

Keywords: Cycling network, QALY, Economic evaluation, Markov model, Cycling, Physical activity

\section{Background}

Studies suggest that cycle-network investments can increase cycling [1-3] and thereby improve health at the population level $[4,5]$. The national and local governmental authorities in Norway have aimed to support the growth of cycling as a means of transportation with the

\footnotetext{
* Correspondence: admassu.lamu@uib.no

'Department of Global Public Health and Primary Care, University of Bergen, Post box 7804, N-5020 Bergen, Norway

Full list of author information is available at the end of the article
}

aim to improve health through increased physical activity. Although building new cycling infrastructure is expensive compared to "soft measures" such as marketing campaigns for cycling promotion [6], improved cycling infrastructure makes cycling safer and more attractive.

The health sector services are increasingly focusing on providing more healthy years for all in Norway [7]. Thus, there is a need to prevent diseases and diminish the adverse impact of long-term medical conditions, and it was shown that physical activity plays a vital role in this 
endeavor [2, 8]. Physical inactivity increases the risk of lifestyle diseases and premature death. Specifically, physical inactivity is one of the leading modifiable risk factors of global mortality, with an estimated $20-30 \%$ increased annual risk of death compared to those who are physically active [9]. Further, physical inactivity was found to be independently responsible for several chronic diseases worldwide, including 6\% of coronary heart disease (CHD), $7 \%$ of type 2 diabetes (T2D), 10\% of breast cancer, and $10 \%$ of colon cancer cases [10]. Thus, promoting physical activity through cycling would have a wide range of potential health benefits in Norway, where the current cycling rate accounts for only $4 \%$ of total transportation journeys [11].

To our knowledge, there have been no studies on cost-effectiveness of cycle-networks construction in Norway. One cost-benefit analysis has been conducted on walking and cycling network investment initiatives in three Norwegian cities (Hokkusund, Hamar, and Trondheim), which utilizes statistical value-of-life methods to quantify the benefits of reduced mortality [12]. However, the health-benefit criterion for health economic evaluation is primarily concerned with health benefits measured in terms of quality-adjusted life-years (QALYs) gained, and can thus be applied to any type of intervention [7]. Cost-effectiveness studies of physical activity that simultaneously model the direct and indirect health benefits are sparse, and none is for Norway. In this study, we assess the cost-effectiveness of planned cycleroute investments in Oslo.

\section{Methods}

\section{Change in cycling rates: regression analysis}

We first address the effect of cycle network expansion on cycling rates. We estimated the change in the mode share of cycling resulting from cycling-network construction using a nonparametric regression method, which makes no assumptions about the functional form of the relationship between the outcome and the covariates. There is a lack of information on the association between the increase in cycle ridership and the construction of cycle roads constructed every year in Norway. Thus, data on cycling mode share and cycling network length were obtained for 123 major European cities with a population size of at least 100,000 from 11 European countries: Austria, Belgium, Denmark, France, Germany, Italy, the Netherlands, Spain, Sweden, Switzerland, and the United Kingdom [13] (Additional file 1). Data on cycling network lengths were retrieved from OpenStreetMap, and data on mode share and population size were obtained through the European Platform on Mobility Management Modal Split Tool [13-15]. The nonparametric regression was extracted using the modal share of cycling (in \%) and cycle-networks length (in $\mathrm{km}$ per
100,000 population) as the independent and dependent variables, respectively. Using the fitted equation, we predicted the percentage of expansion in cycle ridership for every additional $\mathrm{km}$ of cycle length construction.

\section{Model structure: decision analytic model}

We developed a Markov state-transition model that examines the cost-effectiveness of investing in cycle-network construction in Oslo. We refer to the model as the Cyclenetwork Investment Model (CIM), which was developed using the TreeAge Software (๑TreeAge Pro 2020 (v2.1), Williamstown, MA, USA). Markov modeling is commonly used for the evaluation of long-term impact and costeffectiveness of interventions. It is based on a number of mutually exclusive states into which the individual may or may not move at defined points in the future, such as being "physically active" or "physically inactive". The model is reevaluated at different points of time (cycles), and after each cycle, an individual may remain in the previous state or move to a different one depending on transition probabilities. Costs and outcomes (e.g. health) depend on the states and are calculated and cumulated after each cycle. Markov models are particularly well-suited to evaluate population-based health promotion efforts where costs and outcomes appear over an extended period of time [16].

Health outcomes and costs associated with the construction of new cycle networks were compared to the status quo (no intervention). Through CIM, we modeled the incidence of four disease events related to physical activity with and without additional cycling: CHD, stroke, T2D, and cancer. We assumed that only a portion of the cohort chooses cycling as their main means of transportation, and that all cyclists were considered physically active. We allowed for the possibility that some of the non-cyclists could be active elsewhere and achieve similar disease-risk profiles as the cyclists. The insufficiently active (hereafter inactive) group consisted of the portion of the population attaining less than 150 min of moderate-intensity physical activity per week [17]. The proportion of non-cyclists achieving the recommended physical activity level (28.6\%) was obtained from the literature [18]. After cycle-network construction, individuals would settle into either "cyclists" or "non-cyclists", the latter being further subdivided into the two states: "active" and "inactive". The Markov model structure with possible transitions is illustrated in Fig. 1.

The risk of the four specified diseases declined over time for the "active" group. The starting age of the cohort was assumed at 30 years because of the low risk of non-communicable diseases due to physical inactivity before age 30 and the paucity of data on younger age groups. The time horizon of the CIM was assumed to be 25 years on the basis that active travel infrastructure 


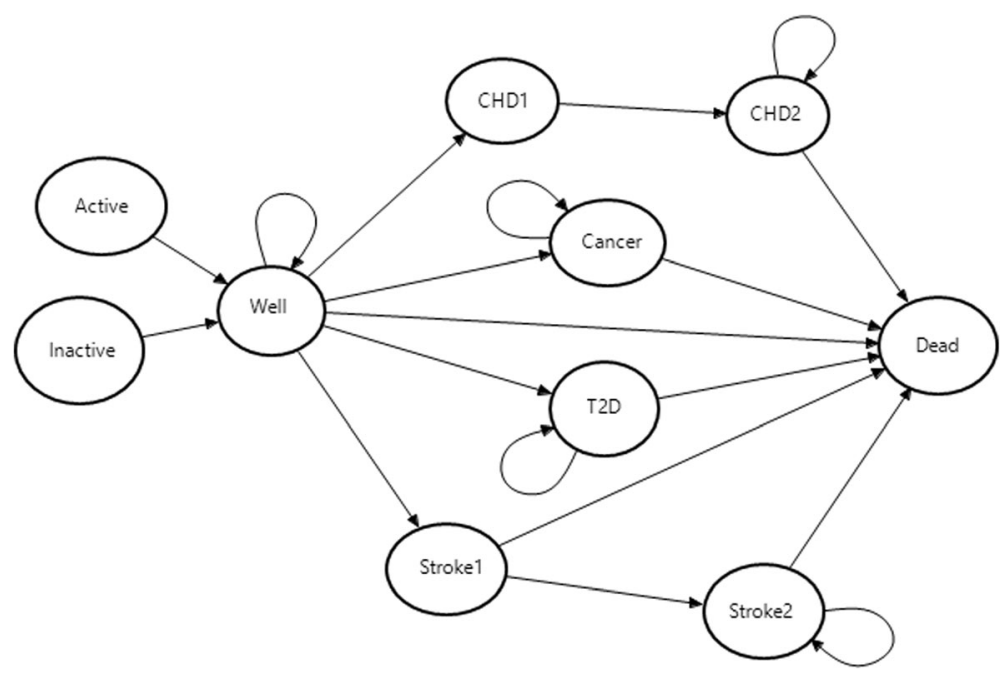

Fig. 1 Markov transition model. Note: Circles represent Markov health states, and arrows indicate the transitions among these health states. Death is an absorbing state from which no future transitions are possible, and Well is a disease-free state from which the Markov process starts. CHD1 fatal coronary heart disease, CHD2 non-fatal coronary heart disease, Stroke1 fatal stroke, Stroke2 non-fatal stroke, T2D type 2 diabetes

might need rebuilding beyond such a horizon, and the model was evaluated using cycle lengths of one year. Future costs and health benefits were discounted at $4 \%$ per year [19]. Willingness-to-pay thresholds of 600,000 NOK $(\$ 72,550)$ were used to determine the likelihood of costeffectiveness in all analyses, which is within the range commonly used in Norway [20, 21].

Initially, we assumed that everyone starts in the "Well" state (i.e. no disease). We assumed that health states included in the model were mutually exclusive, and members do not move between disease states. During each annual cycle, an individual has a risk of moving to one of the disease states or to the "Dead" state. Individuals with T2D and cancer are assumed to either stay in their states or die in the subsequent cycles. For CHD and stroke, we assumed that a given proportion of events would be immediately fatal and people who survived one of these events would have an increased subsequent risk of death. Individuals in the non-fatal states can stay in that state, or move to the "Dead" state. The "Dead" state is absorbing, meaning that no further transitions are possible.

\section{Disease risk and mortality}

We conservatively assumed that the intervention of building new cycle-networks influences the incidence of disease only in healthy participants at risk. Initially, agespecific incidence rates of cancer, CHD, stroke, and T2D for the general Norwegian population were obtained [22, 23]. These incidence rates were then adjusted by population-attributable fractions $[10,24,25]$ to obtain the probabilities of developing these conditions among the inactive individuals (Table 1). Finally, the probabilities of developing the specific diseases among active individuals were derived using relative-risk (RR) estimates identified from the literature (Table 2).

In the absence of direct probabilities for CVD-related and other mortality among individuals with CHD, stroke, and T2D, RRs for these conditions [27, 29, 30] were applied to adjust for age-specific mortality rates (Table 2). Age-specific mortality rates for CVD and allcause mortality were retrieved from Norwegian life tables and cause of death registries [26, 34]. Mortality constituted disease-specific mortality and mortality due to other causes. Mortality due to other causes was given by all-cause mortality less mortality from the four disease conditions included in the model. Individuals with cancer were assigned an increased risk of mortality using data from the Finnish population based registry study [31]. Due to the lack of Norwegian-specific data, case fatality rates for $\mathrm{CHD}$ and stroke were taken from the international literature [27, 28]. Because we are mainly interested in the primary prevention of disease events, the mortality risk from these events (conditional on having the disease), except for T2D, was assumed to be independent of physical activity. For T2D, we also assumed that the risk of death declined over time at a faster rate for the active group than for the inactive group [35, 36].

\section{Cycle-network construction and cycle trips}

The Oslo municipality has an ambitious plan to create a network of $530 \mathrm{~km}$ cycle infrastructure in two phases, where $70 \%$ of the costs are covered by the municipality and the rest by the state government. Phase I is a 100 $\mathrm{km}$ cycle-network to be built by 2025 (i.e., an increase 
Table 1 Age-specific annual probabilities of experiencing the different health events

\begin{tabular}{|c|c|c|c|c|c|c|c|c|}
\hline \multirow[t]{2}{*}{ Age } & \multicolumn{4}{|c|}{ Incidence $[22,23]$} & \multicolumn{2}{|c|}{ Mortality rate [26] } & \multicolumn{2}{|c|}{ Case fatality rate $[27,28]$} \\
\hline & T2D & Cancer & Stroke & CHD & CVD & All-cause & CHD & Stroke \\
\hline 30-34 & 0.0016 & 0.0011 & 0.0003 & 0.0001 & 0.00002 & 0.00046 & 0.0877 & 0.2346 \\
\hline $35-39$ & 0.0018 & 0.0016 & 0.0005 & 0.0003 & 0.00005 & 0.00059 & 0.0877 & 0.2346 \\
\hline $40-44$ & 0.0031 & 0.0022 & 0.0010 & 0.0006 & 0.0001 & 0.00082 & 0.0877 & 0.2346 \\
\hline $45-49$ & 0.0050 & 0.0035 & 0.0017 & 0.0010 & 0.0002 & 0.00136 & 0.0877 & 0.2346 \\
\hline $50-54$ & 0.0076 & 0.0058 & 0.0025 & 0.0018 & 0.0004 & 0.00231 & 0.0877 & 0.2346 \\
\hline $55-59$ & 0.0098 & 0.0087 & 0.0033 & 0.0029 & 0.0007 & 0.00384 & 0.1155 & 0.2328 \\
\hline 60-64 & 0.0106 & 0.0134 & 0.0044 & 0.0046 & 0.0011 & 0.00610 & 0.1155 & 0.2328 \\
\hline $65-69$ & 0.0105 & 0.0190 & 0.0056 & 0.0069 & 0.0020 & 0.01052 & 0.2107 & 0.2347 \\
\hline $70+$ & 0.0121 & 0.0252 & 0.0070 & 0.0102 & 0.0036 & 0.01742 & 0.2107 & 0.2347 \\
\hline
\end{tabular}

from $180 \mathrm{~km}$ in 2015 to $280 \mathrm{~km}$ in 2025). The goal is to increase the share of cycling to $25 \%$ upon the completion of phase I, which is much higher than the base value of $6 \%$ [37].

\section{Costs}

All costs in the CIM are expressed in 2017 US Dollars (\$), and the annual average exchange rate is assumed to be 8.27 NOK per $\$ 1$. All costs were defined as annual costs per person (Table 3). Cost estimations for the treatment of $\mathrm{CHD}$ and stroke were made according to methods described in the NorCaD model [19] and a stroke study in the Norwegian settings [39]. The treatment costs of T2D [40, 41] and cancer [42] were estimated from the literature in a Norwegian context.

The cost of intervention per capita was determined by dividing the total cycle-network investment costs in 2017 by the Oslo population size $(666,759)$ in that year. This was assumed as a prior cost and thus was included in the intervention arm as a one-time cost. Following

Table 2 Relative risk of incidence and mortality for the disease states

\begin{tabular}{llllll}
\hline Disease & \multicolumn{2}{l}{$\begin{array}{l}\text { Base value } \\
\text { RR of } \text { mortality }^{\mathbf{a}}\end{array}$} & $\begin{array}{l}\text { Lower } \\
\text { Upper }\end{array}$ & Distribution & Source \\
\hline CHD & 3.89 & 3.81 & 3.97 & Lognormal & {$[29]$} \\
Stroke & 3.89 & 3.81 & 3.97 & Lognormal & {$[29]$} \\
T2D & 2.61 & 2.34 & 2.88 & Lognormal & {$[30]$} \\
Cancer & 4.20 & 4.00 & 4.30 & lognormal & {$[31]$} \\
& Relative risk for disease & (Active vs inactive) & \\
Cancer & 0.55 & 0.36 & 0.84 & Lognormal & {$[32]$} \\
CHD & 0.80 & 0.75 & 0.86 & Lognormal & {$[33]$} \\
Stroke & 0.82 & 0.77 & 0.87 & Lognormal & {$[33]$} \\
T2D & 0.74 & 0.72 & 0.77 & Lognormal & {$[33]$} \\
\hline
\end{tabular}

aelative risks (RRs) of CVD mortality except for cancer (which is RR of all-cause mortality) the Norwegian Public Roads Administration [38], an average construction cost of 25,000 NOK per meter of cycling networks was used. Following price adjustment and currency conversion, the construction cost was estimated at \$3 million per $\mathrm{km}$. In addition to construction costs, an annual maintenance cost of approximately $7 \%$ of the total investment cost was considered [37, 46].

\section{Outcome measures}

QALYs are the primary outcome measure of the model and were obtained by weighting the time spent in the various health states by the utility values associated with each state. In the present study, health state utility values were measured by the EuroQol five-dimensional questionnaire (EQ-5D) and assigned to all disease states and the healthy state (https://euroqol.org/).

In addition to the direct health effect of cycling, increased physical activity is assumed to improve wellbeing. Only one study was identified that had estimated the relationship between the amount of physical activity and the score on the utility scale [47]. The mentioned study and an analysis performed by the National Institute for Health and Clinical Excellence on promoting physical activity [48] estimated that every $30 \mathrm{~min}$ of physical activity resulted in a QALY gain of $2.22 \times 10^{-4}$ due to improvements in wellbeing. We used this value to transform physical activity levels for the active group into QALYs, which amounted to a QALY gain of over 0.05 per year due to improvements in wellbeing (Table 3).

\section{Sensitivity analyses}

To assess the robustness of the model results and how uncertainties around input values and assumptions might potentially influence them, we carried out scenario and sensitivity analyses. In the scenario analysis, we varied the time horizon of the model from the baseline of 25 years to 20 years and then to 30 years to assess 
Table $\mathbf{3}$ Cost and utility parameters

\begin{tabular}{|c|c|c|c|c|}
\hline Description of Costs and utilities & Cost (\$) and utility values & $S D$ & Distribution for sensitivity analysis & Source \\
\hline \multicolumn{5}{|l|}{ Costs } \\
\hline Investment cost, total/per capita & $3,022,975 / 4.5$ & 1.690 & Gamma & [38] \\
\hline Maintenance cost, total/per capita & $44,438 / 0.066$ & 0.020 & Gamma & [12] \\
\hline Cost of CHD 1st event & 22,133 & 8300 & Gamma & [19] \\
\hline Cost of post-CHD 1st event & 21,597 & 8099 & Gamma & [19] \\
\hline Cost of stroke 1st event & 25,421 & 9533 & Gamma & [19] \\
\hline Cost of post stroke 1st event & 11,962 & 4486 & Gamma & [39] \\
\hline Cost of T2D & 5247 & 1968 & Gamma & {$[40,41]$} \\
\hline Cost of cancer & 13,810 & 5179 & Gamma & {$[42]$} \\
\hline \multicolumn{5}{|l|}{ Utilities } \\
\hline Healthy & 1.00 & & & Assumed \\
\hline Cancer & 0.74 & 0.015 & Beta & [43] \\
\hline CHD1 & 0.47 & 0.016 & Beta & {$[28,44]$} \\
\hline $\mathrm{CHD} 1+$ & 0.56 & 0.016 & Beta & [44] \\
\hline Stroke1 & 0.50 & 0.036 & Beta & [44] \\
\hline Stroke1+ & 0.50 & 0.036 & Beta & [44] \\
\hline $\mathrm{T} 2 \mathrm{D}$ & 0.81 & 0.190 & Beta & [45] \\
\hline Wellbeing gain when active & 0.05 & 0.013 & Beta & {$[28]$} \\
\hline
\end{tabular}

the impact of the time horizon on the cost-effectiveness of the intervention. Scenario analyses for 35 and 40 years of time horizon have also been conducted to check the influence of higher relative risk of the described diseases at an older age. Further, given Oslo's goal of a $25 \%$ mode share for cycling by the year 2025 [37], this study considered four scenarios of cycle mode shares: 11.5, 15, 20, and $25 \%$. In addition, both one-way and probabilistic sensitivity analyses were conducted to explore the effects of key input parameters. In the probabilistic sensitivity analyses (with 10,000 iterations), cost data, probabilities/ utilities, and relative-risk reductions were assumed to follow gamma, beta, and log-normal distributions, respectively. Gamma distributions are constrained on the interval 0 to infinity, and hence appropriate to represent uncertainty in cost parameters; beta distributions are constrained on the interval 0 to 1 and suitable to model uncertainties in probabilities or utilities; and RRs are ratios with confidence limits calculated on the log-scale, and hence log-normal is the appropriate distribution [16].

\section{Results}

\section{Regression results}

The nonparametric regression results show that the average marginal effect of cycle path length is $0.14 \%$; i.e., a one $\mathrm{km}$ increase in length of cycle paths leads to a $0.14 \%$ increase in cycle modal share (Fig. 2). Based on this model, the share of cycling would increase by $3 \%$ if Oslo's cycle- network length increased from $180 \mathrm{~km}$ to $280 \mathrm{~km}$ as per Phase I of the cycle-network expansion plan in Oslo. After adjusting by the base-line value of cycling, the chance of cycling (modal share) after the cycle-network investment becomes $9 \%$. Alternatively, using the fitted model, we predicted that the probability of cycling would increase by $11.5 \%$ if a total of 280 cycle-network $\mathrm{kms}$ were constructed in 2025 . The conservative value of $9 \%$ cycling share is used in the base-case analysis. Other policies may increase the share further, but are not considered here.

\section{Cost-effectiveness analysis: base case analysis}

The total costs, total QALYs, and incremental costeffectiveness ratio for the CIM are presented in Table 4. Cycle-network construction as part of promoting physical activity produced an additional cost of $\$ 416$ per person and yielded 0.019 QALYs per person over the life horizon of the intervention compared with the status quo. The incremental cost per QALY gained (or ICER) is $\$ 22,350$ and thus can be considered highly costeffective at a threshold of $\$ 72,550$ per QALY.

\section{Scenario and sensitivity analyses}

The scenario analyses (Table 4) revealed that the percentage share of cycling (following cycle-network investment) is a crucial parameter. If Oslo achieves its ambitious plan of $25 \%$ modal share for cycling through other forms of physical activity promotion, CIM alone would be cost-effective at $\$ 1548$ per QALY (excluding 


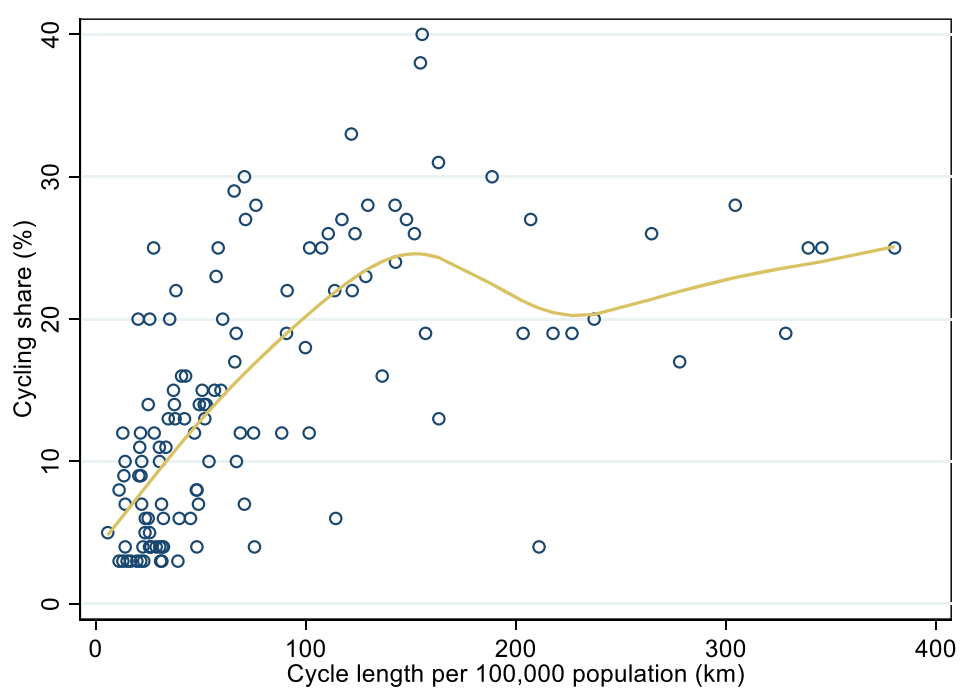

\begin{tabular}{|l|c|c|c|c|}
\hline \multicolumn{1}{|c|}{ Variables } & Estimate & Std. Err. & $\mathrm{P}>|\mathrm{z}|$ & $95 \% \mathrm{Cl}$ \\
\hline Mean & & & & \\
\hline Cycling mode share & 0.1440 & 0.0076 & 0.0000 & $0.1298-0.1587$ \\
\hline Effect & & & & \\
\hline Cycle length & 0.0014 & 0.0002 & 0.0000 & $0.0011-0.0017$ \\
\hline R-squared & 0.5317 & & & \\
\hline
\end{tabular}

Fig. 2 Nonparametric regression between cycle path length (in km per 100,000 population) and cycling mode share

other costs of achieving the planned share of $25 \%$ modal share). Further, reducing the life of the project from 25 to 20 years had a considerable effect: the incremental cost per QALY rose to $\$ 27,967$. In contrast, increasing the life of the project by 10 years (on top of the base-case time horizon of 25 years) reduced the incremental cost per
QALY gained to two-thirds of the base-case value. This substantial reduction in ICER is because the CIM's incremental benefits (or QALY gains) continue to accumulate over an extended duration; at the same time, its incremental costs during the subsequent periods decline due to a reduction in the risk of disease events (Table 4).

Table 4 Cost-effectiveness results comparing CIM with status quo

\begin{tabular}{|c|c|c|c|c|c|c|c|}
\hline \multirow[t]{2}{*}{ CIM } & \multicolumn{2}{|c|}{ Status quo } & \multicolumn{2}{|l|}{ CIM } & \multicolumn{2}{|c|}{ Incremental } & \multirow{2}{*}{$\begin{array}{l}\text { ICER } \\
\text { (\$/QALY) }\end{array}$} \\
\hline & Cost & $\overline{\text { QALY }}$ & Cost & $\overline{\text { QALY }}$ & $\Delta \operatorname{Cost}(\$)$ & $\overline{\triangle Q A L Y}$ & \\
\hline Base case & 6875 & 15.240 & 7291 & 15.259 & 416 & 0.019 & 22,350 \\
\hline \multicolumn{8}{|l|}{ Change cycle share } \\
\hline Predicted cycle share (11.5\%) & 6875 & 15.240 & 7220 & 15.273 & 345 & 0.033 & 10,292 \\
\hline Scenario 2 (15\%) & 6875 & 15.240 & 7188 & 15.297 & 313 & 0.057 & 5533 \\
\hline Scenario 3 (20\%) & 6875 & 15.240 & 7119 & 15.328 & 244 & 0.088 & 2766 \\
\hline Scenario 4 (25\%) & 6875 & 15.240 & 7060 & 15.359 & 185 & 0.119 & 1548 \\
\hline \multicolumn{8}{|l|}{ Time horizon } \\
\hline Scenario 5 (20 years) & 4155 & 13.198 & 4589 & 13.213 & 434 & 0.015 & 27,967 \\
\hline Scenario 6 (30 years) & 10,366 & 16.864 & 10,760 & 16.885 & 394 & 0.021 & 18,536 \\
\hline Scenario 7 (35 years) & 14,420 & 18.139 & 14,782 & 18.163 & 362 & 0.024 & 15,366 \\
\hline Scenario 8 (40 years) & 18,788 & 19.121 & 19,110 & 19.147 & 323 & 0.026 & 12,368 \\
\hline
\end{tabular}


In the one-way sensitivity analysis, the most important variable is the share of cycling, followed by well-being from physical activity (Fig. 3). The lower the cycling share and the wellbeing gain, the higher the ICER. However, plausible changes to the assumed effectiveness of CIM led to ICER estimates that remained well below the threshold of $\$ 72,550$ per QALY. The analysis is generally robust to variations in other key input parameters.

Figure 4 presents a cost-effectiveness acceptability curve and a cost-effectiveness plane for each of the 10,000 simulations. In general, the cost-effectiveness of cycle-network construction compared to the status quo depends on the decision-makers' maximum willingness to pay per additional QALY. The probability that the CIM would be cost-effective at different thresholds of willingness to pay is depicted in Fig. 4a (results produced based on 10,000 Monte Carlo simulations). For example, the ICER for CIM compared with the status quo was considered cost effective at $\$ 30,000$ per QALY, a threshold well below the commonly used value in Norwegian settings (shown by a $\$ 72,550$ per QALY threshold line in Fig. 4b).

\section{Discussion}

This study assessed the cost-effectiveness of new cyclenetwork investment using a Markov state-transition modeling approach. The cycle-network investment compared to the status quo is cost-effective as it is well below the suggested threshold of $\$ 72,550$ per QALY, at which there is a $76 \%$ chance that the CIM will be cost-effective. Setting other benefits aside, health and wellbeing benefits of physical activity justify the investment in cycle infrastructure. This is more cost-effective than other health interventions provided in Norway such as acute ischemic stroke treatment with intravenous thrombolysis through 'mobile stroke unit', which costs nearly two times more (over \$40,000 per QALY gained) [49].

Similar results have been found in previous studies on the cost-effectiveness of cycling infrastructure to improve physical activity, despite the difference in the methodological approaches used. Gu, et al. [50] found that investments in cycle lanes are more cost-effective than the majority of preventive approaches used nowadays. Other studies have also reported positive benefitcost ratios $[1,12,51]$. Recently, there has been a growing need for health economic evaluations of such programs because they assist decision-makers in establishing priorities within cost-constrained health care budgets.

The base-case results were generally robust to probabilistic and deterministic sensitivity analyses. The ICERs modestly decline with an increase in the starting age of the cohort, indicating that the payoffs would be higher if the intervention is targeting older individuals. This makes sense because aging is the main risk factor for the development of multiple non-communicable diseases, including cardiovascular diseases, cancer and diabetes.

This study is timely because it is relevant to the ongoing public and political debate about public health interventions in Norway, and addresses the lack of economic evidence on public health interventions. Another strength is the quantitative analysis of wider health

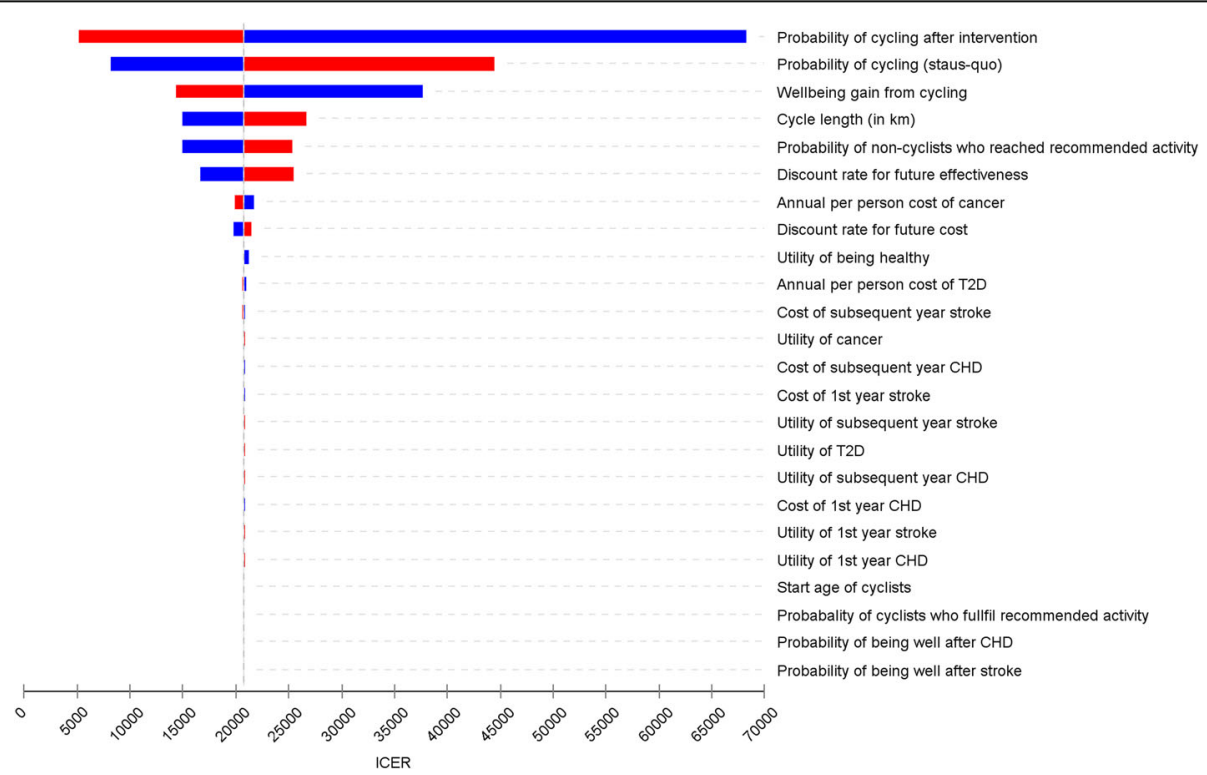

Fig. 3 An influence analysis (Tornado diagram). CHD coronary heart disease, T2D type-2 diabetes, ICER incremental cost-effectiveness ratio. Each bar represents the range of outcomes produced when each input parameters is set to low (blue bar) and high values (red bar), with the other variables being held constant. The solid vertical line represents the value of the outcome when the baseline values are used for all input parameters. The upper bars represent input parameters that contribute most to the variability of the outcome 


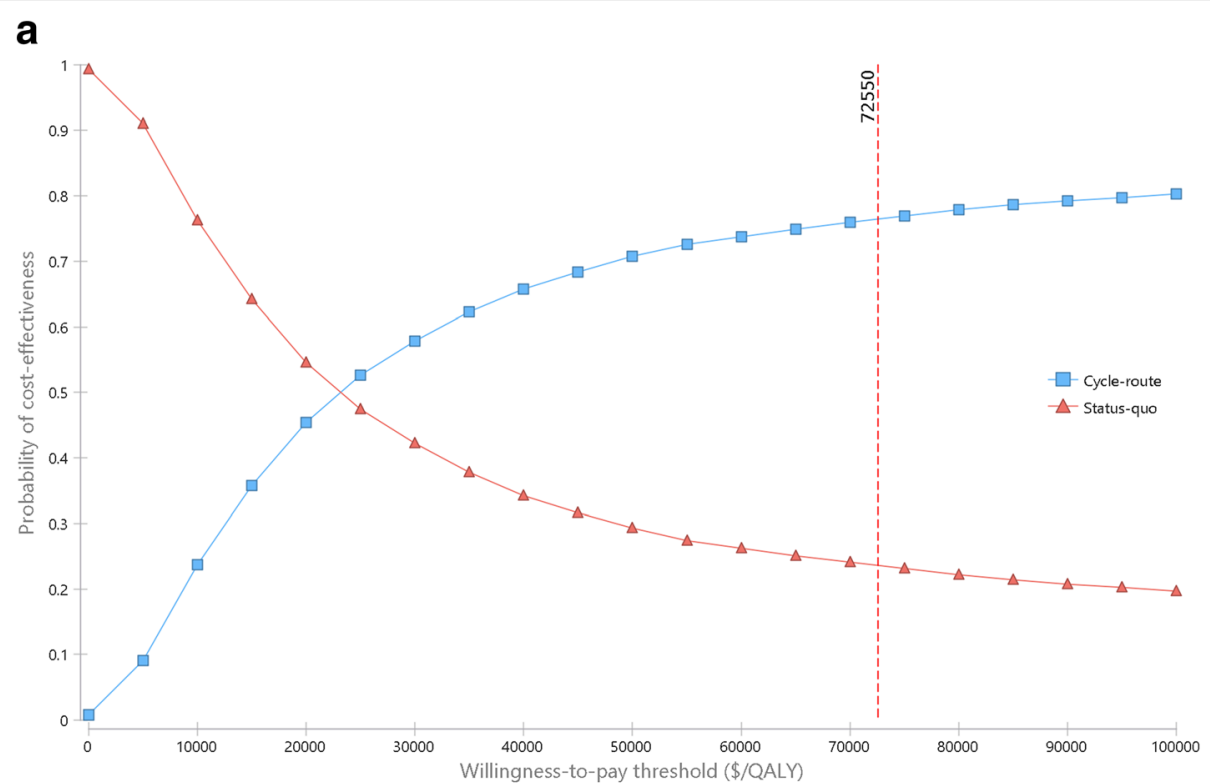

b

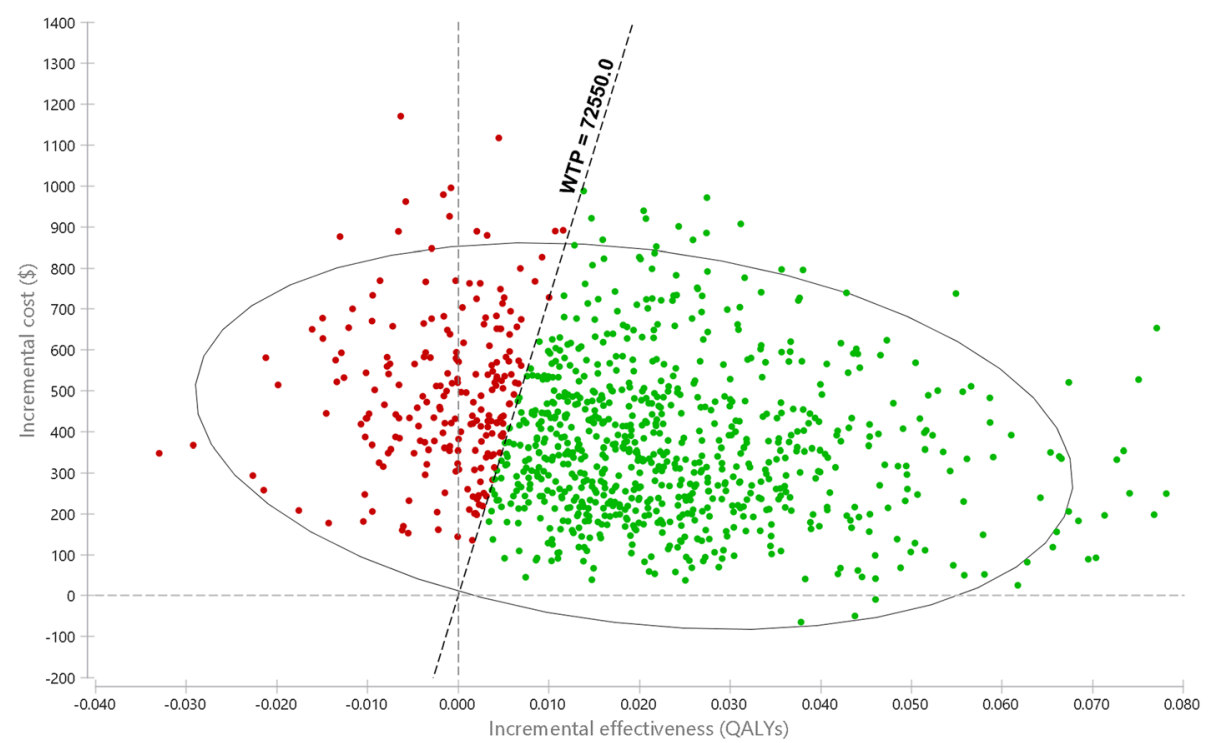

Fig. 4 Cost-effectiveness acceptability curve and cost-effectiveness plane showing results for 10,000 Monte Carlo simulations

aspects (including wellbeing) associated with the cycling infrastructure. The use of a Markov model is also a strength because it represents processes that evolve over time, which is particularly suited for modelling the progression of chronic disease and interventions (e.g., cycling) that aim to reduce the risk or severity of diseases. However, the study has a number of limitations. Costs and utility data were taken from secondary sources. To minimize the effect of such limitations, data from Norway were used as much as possible. In the absence of such data, information from similar studies was carefully retrieved from similar countries and reported here with transparency. Further, uncertainty in the cost and utility estimates was incorporated and analyzed in the model through deterministic and probabilistic sensitivity analyses.

The model included only cycle-network investment and health care costs, and the results might vary if other costs and productivity changes are included. In addition, we might have underestimated the benefits of the program by considering that the intervention only modifies disease incidence, while it may also reduce the risk of mortality [52]. Uncertainty with regard to gain in QALY due to improvement in wellbeing resulting from increased share of cycling could be another limitation, and we might have overestimated the benefits if there is no 
or only trivial wellbeing gain. Furthermore, the assumption that all cyclists are active might not always hold because an increase in cycling might not translate directly into an equivalent increase in overall physical activity. Had only $90 \%$ of cyclists been assumed to be active, the incremental cost per QALY would have increased by $11 \%$.

Other disease conditions that may be affected by physical activity were excluded from the analysis. Such assumptions might lead to underestimation of the costeffectiveness of the CIM. The exclusion of adverse effects of cycling (e.g., injuries), and additional favorable effects of cycling (e.g., reduced air pollution and congestion as well as wear and tear of roadways) constitute another limitation. However, injuries are generally low and less likely to significantly affect the results at the population level [27]. Further, it has been argued that the net number of fatalities and crashes would not increase with investments in cycling [51]. The issue of air pollution is also dynamic in the sense that cyclists could potentially be exposed to higher doses of pollution even though cycling reduces overall pollution emissions. The basecase analysis assumed cost-effectiveness of cyclenetworks investment for people starting to ride cycle at the age of 30 over the next 25 years (i.e., from age 30 to 55 years). This simplifying assumption likely yields conservative estimates, because prevalence of the diseases and preventable mortality increase among older age groups. We considered time horizons up to 40 years in scenario analyses, and found that cycle-network investment becomes more cost-effective with longer analytical horizons.

In cost-benefit analysis terms, the health benefits (only) measured in monetary terms (value of statistical life estimates), which are often used in the transport sector, would clearly be substantially larger than the investment costs. Thus, our study can reasonably justify the need for further investment in cycle-networks as a crucial part of improvements in health and wellbeing as well as having an efficient urban infrastructure.

\section{Conclusions}

The findings of this study show that investments in cyclenetwork construction in Oslo would be cost-effective. Cycling can be done as part of daily travel routines, and thus has the potential to reduce the risk of a range of health conditions, mainly cancer, heart disease, T2D, and stroke - all of which are preventable causes of premature death. It can also delay mortality if such diseases develop. Our findings provide evidence that cycle-networks investment may help increase overall physical activity levels and thereby produce substantial health benefits. Thus, policymakers should focus on placing cycling at the heart of a healthy transport policy making cycling a convenient, safe, and attractive everyday activity.

\section{Supplementary Information}

The online version contains supplementary material available at https://doi. org/10.1186/s12889-020-09764-5.

Additional file 1. Cycling network and mode share data for 123 major European cities.

\section{Abbreviations}

CIM: Cycle-networks Investment Model; QALY: Quality-Adjusted Life Year; CHD: Coronary Heart Disease; T2D: Type 2 Diabetes; CVD: Cardiovascular Disease; EQ-5D: EuroQol 5-Dimensional Questionnaire; ICER: Incremental Cost-Effectiveness Ratio; RR: Relative Risk

\section{Acknowledgements}

The draft of this manuscript was presented at the 26th Annual Conference of the International Society for Quality of Life research (ISOQOL), San Diego, California, USA, Oct 20-23, 2019. We acknowledge the ISOQOL Conference for publishing the abstract in their conference proceedings [53].

\section{Authors' contributions}

ANL was responsible for the general coordination of the study and the design and analysis of the economic model with inputs from AJ and BR. $A N L, A J, S V$ and OFN designed the study. ANL, AJ and BR led the statistical analyses. ANL wrote the first draft. All authors reviewed the manuscript, and approved the final version of the manuscript

\section{Funding}

This study was funded by The Research Council of Norway (grant number 260588). The funding body has no role in the design of the study, statistical analyses or interpretation of the results.

\section{Availability of data and materials}

The datasets generated and/or analyzed during the current study are available in OpenStreetMap and European Platform on Mobility

Management (EPOMM) repository (openstreetmap.org and epomm.eu/tems/ about tems.phtml) and are included in this article as an online

supplementary material.

Ethics approval and consent to participate

Not applicable.

Consent for publication

Not applicable.

\section{Competing interests}

The authors declare that they have no competing interests.

\section{Author details}

'Department of Global Public Health and Primary Care, University of Bergen, Post box 7804, N-5020 Bergen, Norway. ${ }^{2}$ Department of Global Health and Population, Harvard T.H. Chan School of Public Health, Boston, MA, USA.

Received: 25 March 2020 Accepted: 26 October 2020

Published online: 07 December 2020

\section{References}

1. Chapman R, Keall M, Howden-Chapman P, Grams M, Witten K, Randal E, Woodward A. A cost benefit analysis of an active travel intervention with health and carbon emission reduction benefits. Int J Environ Res Public Health. 2018;15(5):962. https://doi.org/10.3390/ijerph15050962.

2. Goodman A, Sahlqvist S, Ogilvie D. New walking and cycling routes and increased physical activity: one- and 2-year findings from the UK iConnect study. Am J Public Health. 2014;104(9):e38-46. https://doi.org/10.2105/ajph. 2014.302059. 
3. Panter J, Ogilvie D. Cycling and diabetes prevention: practice-based evidence for public health action. PLoS Med. 2016;13(7):e1002077. https:// doi.org/10.1371/journal.pmed.1002077.

4. Handy S, van Wee B, Kroesen M. Promoting cycling for transport: research needs and challenges. Transp Rev. 2014;34(1):4-24. https://doi.org/10.1080/ 01441647.2013 .860204 .

5. Schepers P, Fishman E, Beelen R, Heinen E, Wijnen W, Parkin J. The mortality impact of bicycle paths and lanes related to physical activity, air pollution exposure and road safety. J Transp Health. 2015;2(4):460-73. https://doi.org/ 10.1016/j.jth.2015.09.004

6. Golbuff LaA R. Cycling policy in the UK: a historical and thematic overview. London: University of East London Sustainable Mobilities Research Group; 2011.

7. Ottersen T, Forde R, Kakad M, Kjellevold A, Melberg HO, Moen A, Ringard A, Norheim OF. A new proposal for priority setting in Norway: Open and fair. Health policy (Amsterdam, Netherlands). 2016;120(3):246-51. https://doi.org/ 10.1016/j.healthpol.2016.01.012

8. Hoevenaar-Blom MP, Wendel-Vos GC, Spijkerman AM, Kromhout D, Verschuren WM. Cycling and sports, but not walking, are associated with 10-year cardiovascular disease incidence: the MORGEN study. European J Cardiovascular Prevent Rehab. 2011;18(1):41-7. https://doi.org/10.1097/HJR.0b013e32833bfc87.

9. Fletcher GF, Landolfo C, Niebauer J, Ozemek C, Arena R, Lavie CJ. Promoting physical activity and exercise: JACC health promotion series. J Am Coll Cardiol. 2018;72(14):1622-39. https://doi.org/10.1016/j.jacc.2018.08.2141.

10. Lee IM, Shiroma EJ, Lobelo F, Puska P, Blair SN, Katzmarzyk PT. Effect of physical inactivity on major non-communicable diseases worldwide: an analysis of burden of disease and life expectancy. Lancet. 2012;380(9838): 219-29. https://doi.org/10.1016/s0140-6736(12)61031-9.

11. Lunke EB, Grue B. Cycling and cycling goals [in Norwegian]. Oslo: Norwegian Public Roads Administration (TØI); 2018. https://www.toi.no/ getfile.php?mmfileid=49561. Accessed 12 Dec 2019.

12. Saelesminde K. Cost-benefit analyses of walking and cycling track networks taking into account insecurity, health effects and external costs of motorized traffic. Transp Res A. 2004;38(8):593-606.

13. Mueller N, Rojas-Rueda D, Salmon M, Martinez D, Ambros A, Brand C, de Nazelle A, Dons E, Gaupp-Berghausen M, Gerike R, et al. Health impact assessment of cycling network expansions in European cities. Prev Med. 2018;109:62-70. https://doi.org/10.1016/j.ypmed.2017.12.011.

14. OpenStreetMap contributors. Planet Dump. 2019. https://www. openstreetmap.org. Accessed 10 Dec 2019.

15. EPoMM. European Platform on Mobility Management (EPOMM) Modal Split Tool (TEMS). 2011. http://www.epomm.eu/tems/about_tems.phtml. Accessed 15 Dec 2019

16. Briggs A, Claxton K, Sculpher M. Decision Modelling for health economic evaluation. Oxford: OUP; 2006.

17. WHO. Global recommendations on physical activity for health. Geneva: WHO; 2010. https://www.who.int/dietphysicalactivity/factsheet_ recommendations/en/. Accessed 20 Jul 2020.

18. Raser E, Gaupp-Berghausen M, Dons E, Anaya-Boig E, Avila-Palencia I, Brand C, Castro A, Clark A, Eriksson U, Götschi T, et al. European cyclists' travel behavior: differences and similarities between seven European (PASTA) cities. J Transp Health. 2018;9:244-52. https://doi.org/10.1016/j.jth.2018.02.006.

19. Wisløff T, Selmer RM, Halvorsent S, Kristiansen IS. Norwegian Cardiovascular Disease Model (NorCaD) - a simulation model for estimating health benefits and cost consequences of cardiovascular interventions (No. 23/2008). Oslo: Norwegian Knowledge Centre for the Health Services (NOKC); 2008.

20. Korman M, Wisløff T. Modelling the cost-effectiveness of PCSK9 inhibitors vs. ezetimibe through LDL-C reductions in a Norwegian setting. Eur Heart J Cardiovascular pharmacother. 2018;4(1):15-22. https://doi.org/10.1093/ ehjcvp/pvx010.

21. $\mathrm{NDoH}$. Economic evaluation of health interventions-a guideline [In Norwegian]. Oslo: Norwegian Directorate of Health (NDoH); 2012. https:// www.helsedirektoratet.no/veiledere/okonomisk-evaluering-av-helsetiltak/\% C3\%98konomisk\%20evaluering\%20av\%20helsetiltak\%20\%E2\%80\%93\%2 OVeileder.pdf/. Accessed 15 Jul 2020.

22. GBD Collaborative Network. Global Burden of Disease Study 2017 (GBD 2017) Results. Seattle: Institute for Health Metrics and Evaluation (IHME); 2018. http://ghdx.healthdata.org/gbd-results-tool. Accessed 10 Jun 2019.

23. Cancer Registry of Norway. Cancer in Norway 2017 - Cancer incidence, mortality, survival and prevalence in Norway. Oslo: Cancer Registry of Norway; 2018. https://www.kreftregisteret.no/globalassets/cancer-innorway/2017/cin-2017.pdf. Accessed 05 Apr 2019.
24. Bolin K. Physical inactivity: productivity losses and healthcare costs 2002 and 2016 in Sweden. BMJ Open Sport Exerc Med. 2018;4(1):e000451. https://doi. org/10.1136/bmjsem-2018-000451.

25. Feigin VL, Roth GA, Naghavi M, Parmar P, Krishnamurthi R, Chugh S, Mensah GA, Norrving B, Shiue I, Ng M, et al. Global burden of stroke and risk factors in 188 countries, during 1990-2013: a systematic analysis for the global burden of disease study 2013. The Lancet Neurology. 2016;15(9):913-24. https://doi.org/10.1016/\$1474-4422(16)30073-4.

26. NIPH. The cause of death register's statistics bank [in Norwegian]. Oslo: Norwegian Institute of Public Health (NIPH); 2019. [http://statistikkbank.fhi. no/webview/]. Accessed 20 Apr 2019.

27. Anokye NK, Lord J, Fox-Rushby J. Is brief advice in primary care a costeffective way to promote physical activity? Br J Sports Med. 2014;48(3):202. https://doi.org/10.1136/bjsports-2013-092897.

28. Ward S, Lloyd Jones M, Pandor A, Holmes M, Ara R, Ryan A, Yeo W, Payne N. A systematic review and economic evaluation of statins for the prevention of coronary events. Health Technol Assess. 2007;11(14):1-160 iii-iv.

29. Brønnum-Hansen H, Davidsen M, Thorvaldsen P. Long-term survival and causes of death after stroke. Stroke. 2001;32(9):2131-6. https://doi.org/10.1161/hs0901.094253.

30. Preis SR, Hwang SJ, Coady S, Pencina MJ, D'Agostino RB Sr, Savage PJ, Levy D, Fox CS. Trends in all-cause and cardiovascular disease mortality among women and men with and without diabetes mellitus in the Framingham heart study, 1950 to 2005. Circulation. 2009;119(13):1728-35. https://doi.org/ 10.1161/circulationaha.108.829176.

31. Kero AE, Järvelä LS, Arola M, Malila N, Madanat-Harjuoja LM, Matomäki J Lähteenmäki PM. Late mortality among 5-year survivors of early onset cancer: a population-based register study. Int J Cancer. 2015;136(7):1655-64 https://doi.org/10.1002/ijc.29135.

32. Celis-Morales CA, Lyall DM, Welsh P, Anderson J, Steell L, Guo Y, Maldonado R, Mackay DF, Pell JP, Sattar N, et al. Association between active commuting and incident cardiovascular disease, cancer, and mortality: prospective cohort study. BMJ (Clinical research ed). 2017;357:j1456. https://doi.org/10. 1136/bmj.j1456.

33. Wahid A, Manek N, Nichols M, Kelly P, Foster C, Webster P, Kaur A, Friedemann Smith C, Wilkins E, Rayner M, et al. Quantifying the association between physical activity and cardiovascular disease and diabetes: a systematic review and meta-analysis. J Am Heart Assoc. 2016;5(9):e002495. https://doi.org/10.1161/JAHA.115.002495.

34. SSB. StatBank Norway. Oslo: Statistics Norway (SSB). https://www.ssb.no/en/ statbank (2020). Accessed 15 Jul 2020

35. Hu G, Jousilahti P, Barengo NC, Qiao Q, Lakka TA, Tuomilehto J. Physical activity, cardiovascular risk factors, and mortality among Finnish adults with diabetes. Diabetes Care. 2005;28(4):799. https://doi.org/10.2337/diacare.28.4.799.

36. Sluik D, Buijsse B, Muckelbauer R, Kaaks R, Teucher B, Johnsen NF, Tjønneland A, Overvad K, Østergaard JN, Amiano P, et al. Physical activity and mortality in individuals with diabetes mellitus: a prospective study and meta-analysis. Arch Intern Med. 2012;172(17):1285-95. https://doi.org/10. 1001/archinternmed.2012.3130.

37. Oslo Kommune. Plan for the cycle path network in Oslo [in Norwegian] Oslo Municipality: Oslo; 2018. https://www.oslo.kommune.no/gate-transportog-parkering/sykkel/sykkelstrategier-og-dokumenter/\#gref. Accessed 12 May 2019.

38. Espeland M, Amundsen KS. National cycling strategy 2014-2023: base document for national transport plan 2014-2023 [in Norwegian]. Oslo: The Norwegian Public Road Administration; 2012. http://hdl.handle.net/11250/25 77105. Accessed 10 May 2019.

39. Fjaertoft H, Indredavik B, Magnussen J, Johnsen R. Early supported discharge for stroke patients improves clinical outcome. Does it also reduce use of health services and costs? One-year follow-up of a randomized controlled trial. Cerebrovasc Dis. 2005;19(6):376-83. https://doi.org/10.1159/000085543.

40. Solli O, Jenssen T, Kristiansen IS. Diabetes: cost of illness in Norway. BMC Endocr Disord. 2010;10:15-5. https://doi.org/10.1186/1472-6823-10-15.

41. Sorensen M, Arneberg F, Line TM, Berg TJ. Cost of diabetes in Norway 2011. Diabetes Res Clin Pract. 2016;122:124-32. https://doi.org/10.1016/j.diabres. 2016.10.012

42. OsloEconomics. Cancer costs in Norway: Costs for patients, health care services and the society [In Norwegian]. Oslo: Oslo Economics; 2016. http:// oslocancercluster.no/wp-content/uploads/2016/10/20161004Kreftkostnader_i_Norge-WEB.pdf. Accessed Dec 052019.

43. Saarni SI, Harkanen T, Sintonen $\mathrm{H}$, Suvisaari J, Koskinen S, Aromaa A Lonnqvist J. The impact of 29 chronic conditions on health-related quality 
of life: a general population survey in Finland using 15D and EQ-5D. Qual Life Res. 2006;15(8):1403-14. https://doi.org/10.1007/s11136-006-0020-1.

44. Verhaeghe N, De Smedt D, De Maeseneer J, Maes L, Van Heeringen C, Annemans $L$. Cost-effectiveness of health promotion targeting physical activity and healthy eating in mental health care. BMC Public Health. 2014; 14(1):856. https://doi.org/10.1186/1471-2458-14-856.

45. Solli O, Stavem K, Kristiansen IS. Health-related quality of life in diabetes: the associations of complications with EQ-5D scores. Health Qual Life Outcomes. 2010;8:18-8. https://doi.org/10.1186/1477-7525-8-18.

46. TØI. The bicycle calculator: Web-based cycling tool [In Norwegian]. Working Dokument 50908. Oslo: Institute of Transport Economics (TøI). 2016. https:// www.toi.no/sykkelkalkulator/dokumentasjon.pdf. Accessed 10 May 2019.

47. Beale S, Bending M, Trueman P. An Economic Analysis of Environmental Interventions that Promote Physical Activity: PDG Report York: University of York; 2007.

48. NICE. Promoting physical activity for children and young people. London: National Institute for Health and Clinical Excellence; 2009. https://www.nice. org.uk/guidance/ph17/evidence/cost-effectiveness-analysis-371241757. Accessed 27 May 2019

49. Ormstad SS, Lund UH, Chudasama KK, Frønsdal KB, Hov MR, Ormberg I, Hafstad E, Stoinska-Schneider A, Robberstad B, Lauvrak V, et al. Prehospital $\mathrm{C} T$ for early diagnosis and treatment of suspected acute stroke or severe head injury. A health technology assessment. Oslo: Norwegian Institute of Public Health (NIPH); 2019. https://www.fhi.no/publ/2019/prehospital-ct-fortidlig-diagnostikk-og-behandling-ved-mistanke-om-hjernes/. Accessed 15 Nov 2019

50. Gu J, Mohit B, Muennig PA. The cost-effectiveness of bike lanes in New York City. Injury Prevention. 2017;23(4):239. https://doi.org/10.1136/injuryprev2016-042057.

51. Gotschi T. Costs and benefits of bicycling investments in Portland, Oregon. J Phys Act Health. 2011;8(Suppl 1):S49-58.

52. Kelly P, Kahlmeier S, Götschi T, Orsini N, Richards J, Roberts N, Scarborough $\mathrm{P}$, Foster C. Systematic review and meta-analysis of reduction in all-cause mortality from walking and cycling and shape of dose response relationship. Int J Behav Nutr Phys Act. 2014;11(1):132. https://doi.org/10. 1186/s12966-014-0132-x.

53. Lamu AN, Jbaily A, Verguet SP, Norheim OF. Health benefits of new cyclepath construction: cost-effectiveness analysis with a Markov model [abstract]. In: Abstracts Presented at the $26^{\text {th }}$ Annual Conference of the International Society for Quality of Life Research; 2019 Oct 20-23, San Diego, California, United States. Qual Life Res. 2019;28:1-190. https:/doi.org/ 10.1007/s11136-019-02257-y.

\section{Publisher's Note}

Springer Nature remains neutral with regard to jurisdictional claims in published maps and institutional affiliations.

Ready to submit your research? Choose BMC and benefit from:

- fast, convenient online submission

- thorough peer review by experienced researchers in your field

- rapid publication on acceptance

- support for research data, including large and complex data types

- gold Open Access which fosters wider collaboration and increased citations

- maximum visibility for your research: over $100 \mathrm{M}$ website views per year

At $\mathrm{BMC}$, research is always in progress.

Learn more biomedcentral.com/submissions 